\title{
Relationship between Giant Panda Ailuropoda melanoleuca Habitat use and Disturbance Density in the Daxiangling Mountains, Sichuan, China
}

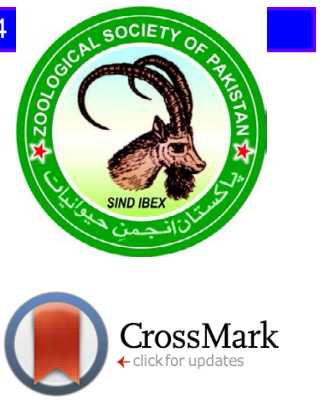

\author{
Cheng Zhao ${ }^{1,2}$, Jianghong Ran ${ }^{2 *}$, Bin Wang ${ }^{2,3}$, Qin Shi ${ }^{4}$ and Marwan M.A. Rashed ${ }^{1}$ \\ ${ }^{1}$ College of Life Sciences and Food Engineering, Yibin University, Yibin 644007, \\ P. R. China. \\ ${ }^{2}$ Key Laboratory of Bio-Resource and Eco-Environment of Ministry of Education, \\ College of Life Sciences, Sichuan University, Chengdu 610065, P. R. China \\ ${ }^{3}$ Key Laboratory of Southwest China Wildlife Resources Conservation (Ministry of \\ Education), Institute of Ecology, China West Normal University, Nanchong 637009, \\ P. R. China. \\ ${ }^{4}$ Academic Affair Office, Yibin University, Yibin 644007, P. R. China.
}

Article Information
Received 06 November 2018
Revised 12 March 2019
Accepted 06 May 2019
Available online 25 August 2020
Authors' Contribution
CZ and BW are the main contributors
of this research. JR is the person in
charge of this project. QS and MMAR
revised the manuscript.
Key words
Giant panda, Daxiangling mountains,
Disturb density, Road, Conservation

\begin{abstract}
A B S T RA C T
The giant panda Ailuropoda melanoleuca is one of the most iconic mammals in the world. The species has experienced declines in its habitat and population due to human disturbance. To protect this species, we investigated the relationship between giant panda habitat use intensity and human disturbance density in the Daxiangling Mountains. The results indicated that, among multiple kinds of disturbances, roads affected the giant panda habitat use significantly. In addition, roads caused the giant panda habitat use intensity to decline sharply. The giant panda nearly stopped using the habitat when road density was more than $0.4 \mathrm{~km} / \mathrm{km}^{2}$. Thus, road density should be considered in the protection program. Furthermore, in areas inhabited by giant pandas, we recommend to optimizing and enhancing increased regulations to minimize the expansion and impact of roads.
\end{abstract}

\section{INTRODUCTION}

$\mathrm{T}^{\mathrm{s}}$ he giant panda Ailuropoda melanoleuca was one of the most threatened mammals once. Although it is categorized as Vulnerable on the IUCN Red List (Swaisgood et al., 2016), keeping in view the importance of the animal in the conservation world perspective, the protection work should not be ignored, especially the small population in the Daxiangling Mountains, where pandas remain threatened by various human disturbances (Sichuan Provincial Forestry Department, 2015).

Understanding how human activities affect pandas is essential for effective management and protection of this species. Human disturbances are known to affect wild animals in many ways. Roads and logging lead to forest loss and habitat fragmentation (Way, 1977;

\footnotetext{
* Corresponding author: rjhong-01@163.com

0030-9923/2020/0006-2129 \$ 9.00/0

Copyright 2020 Zoological Society of Pakistan
}

Van Dyke et al., 1986; Andrews, 1990; Carr et al., 2002; Zhao et al., 2014), consequently reducing genetic exchange (Zhu et al., 2010; Zhu et al., 2011; Qi et al., 2012). Hunting can threaten local populations; for example, in Baoxing County, 117 giant pandas were hunted before 1989 (Hu, 2001). Human disturbance decreases species richness (Suntsov et al., 2009).

Many studies showed that disturbance density could affect wildlife habitat use. Forman (1995) pointed that, with some species, a threshold could be found in the relationship between animal population density and behavior and road density. In some researches, this threshold has been demonstrated. For example, moose Alces alces exhibited a pronounced response to roads when road density reached approximate threshold of 0.4 and $0.2 \mathrm{~km} / \mathrm{km}^{2}$ in winter and summer respectively (Beyer et al., 2013). In the case of the giant panda, the influence of many aspects of human disturbance has be investigated (Ran et al., 2003; Li et al., 2003; Bearer et al., 2008; Zeng et al., 2009; Gong et al., 2012; Zhao et al., 2017). However, few studies have 
focused on the relationship between giant panda habitat use and disturbance density, hence leaving a lacuna in the process of development of a comprehensive protection plan.

To obtain more knowledge about how human disturbance affects giant pandas, we studied the relationship between giant panda habitat use and human disturbance density in the Daxiangling Mountains. Our main goals were to determine which kinds of disturbance had greater influence on the habitat use of giant pandas; to investigate how the impacts of disturbance on habitat use varied with disturbance density; and suggesting measures to improve conservation plans for the giant panda according to the results of our studies.

\section{MATERIALS AND METHODS}

\section{Study area}

The field survey was conducted in the Daxiangling Mountains, Sichuan, China (Fig. 1). The climate is humid, the mean annual temperature is $16^{\circ} \mathrm{C}$ and annual rainfall is $1,300-2,000 \mathrm{~mm}(\mathrm{Hu}, 2001)$. The vegetation is mainly broad-leaved forest below $1,500 \mathrm{~m}$ elevation, at $1,500-2,500 \mathrm{~m}$ it is mainly mixed forest, and above $2,500 \mathrm{~m}$ it is primarily coniferous forest $(\mathrm{Hu}, 2001)$. The highest peak is 3,552 m. In the Daxiangling Mountains, the primary human disturbances are roads, hydropower stations, residences, mining, collection of bamboo shoots, logging and trapping (Ran et al., 2006; Sichuan Provincial Forestry Department, 2015).

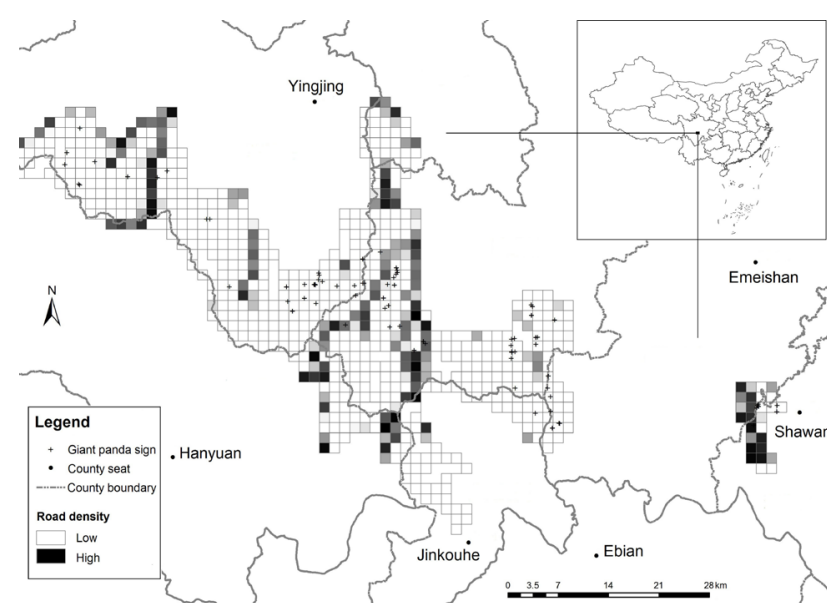

Fig. 1. The locations of giant panda signs in the study area in the Daxiangling Mountains, Sichuan, China.

\section{Methods}

The study area was divided into $6882-\mathrm{km}^{2}$ plots (Fig. 1) and surveyed by 30 investigators during May-
September 2012. Investigators followed a transect greater than $1.5 \mathrm{~km}$, searching for signs (e.g. faeces, signs of feeding) of giant pandas in each plot. If signs of the giant panda could be found in a plot, the plot was treated as a giant panda used plot. If a plot satisfied both of the following requirements, it was treated as a non-use plot. i. No signs had been found in the plot, and ii. No signs had been found in neighboring eight plots (because the radius of the giant panda's home range is about $1.5 \mathrm{~km}(\mathrm{Hu}, 2001)$. Signs of giant pandas were geographically referenced using a GPS. GPS readings were also recorded at all locations of human disturbance i). Roads, ii). Residences, iii). Hydropower stations, iv). Mines, v). Bamboo shoot collection sites, vi). Logging and tree-felling sites and vii). Trap sites). The road system was obtained from Google Earth (Google Inc., Mountain View, USA) and government maps. As all the roads used by four-wheeled vehicles within the study area had analogous characteristics, roads were treated as one type of disturbance in this study.

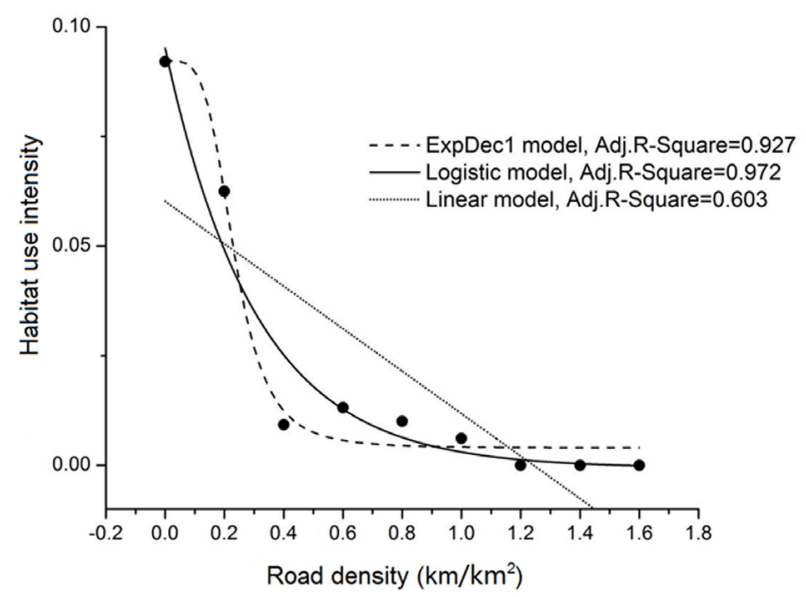

Fig. 2. Line and curve-fitting analysis of the relationship between the giant panda's habitat use intensity and road density.

We analysed the relationship between giant panda habitat use and human disturbance density in two steps. Firstly, we investigated which types of disturbance were the main factors affecting giant panda habitat use. Secondly, we studied how the influence of the main types of disturbance on the intensity of giant panda habitat use varied from the disturbance density.

We conducted independent sample $t$ tests to compare variables between used plots and non-use plots when data were normally distributed, Mann-Whitney $\mathrm{U}$ tests were used when the distributional assumptions were not met. Then, Binary Logistic Regression with a forward stepwise procedure was employed, plot type 
Table I. Significant difference analysis on density between the gird giant panda used and not used.

\begin{tabular}{|c|c|c|c|c|}
\hline \multirow[t]{2}{*}{ Variables } & \multicolumn{2}{|c|}{ Mean \pm SD } & \multirow[t]{2}{*}{$\mathbf{U}$} & \multirow[t]{2}{*}{$\mathbf{F}$} \\
\hline & Use plot & Non-use plot & & \\
\hline Road & $0.16 \pm 0.58$ & $0.43 \pm 0.90$ & & $0.002 * *$ \\
\hline Residence & $0.05 \pm 0.21$ & $0.07 \pm 0.27$ & & 0.579 \\
\hline Mine & $0.02 \pm 0.12$ & $0.06 \pm 0.31$ & 0.321 & \\
\hline Hydropower station & $0.05 \pm 0.21$ & $0.10 \pm 0.39$ & 0.585 & \\
\hline Logging or tree-feeling site & $0.03 \pm 0.18$ & $0.06 \pm 0.30$ & & 0.523 \\
\hline Bamboo shoot collection site & $0.13 \pm 0.42$ & $0.06 \pm 0.30$ & & 0.109 \\
\hline Trap site & $0.07 \pm 0.25$ & $0.03 \pm 0.22$ & 0.114 & \\
\hline
\end{tabular}

$\mathrm{U}$ stand for Mann-Whitney $\mathrm{U}$ tests, F stand for independent sample t tests, ** indicate the value of $P<0.01$

(used plots and non-use plots) was treated as the dependent variable, while disturbances were the independent variables. To investigate the influence of the main types of disturbance on the intensity of habitat use varying from the disturbance density, the disturbance density was divided into nine degrees. The giant panda habitat use intensity in each disturbance density degree was counted from giant panda signs. Linear, logistic and exponential decay-fitting analyses were used to visualize the relationship between disturbance density and habitat use intensity and to test if a threshold could be found visually.

Table II. Variables to distinguish habitat from non-use plots through logistic regression.

\begin{tabular}{llll}
\hline Variable & B & Wald & P \\
\hline Road & $-5.614 \mathrm{E}-4$ & 4.719 & 0.030 \\
Constant & -2.192 & 239.444 & 0.000 \\
\hline
\end{tabular}

B stand for the regression coefficients, Wald stand for Chi-square value, $P$ stand for $P$ value.

\section{RESULTS}

101 locations of giant panda signs and 301 locations of human disturbance (63 residences, 76 hydropower stations, 45 mines, 48 bamboo shoot collection sites, 35 logging or tree-felling sites and 34 trap sites) were recorded. The distribution of giant panda signs and roads is presented in Figure 1.

Only roads showed a difference between used plots and non-use plots (Table I). By logistic regression analysis, only road disturbance entered into the final model and made a significant contribution to used plots from non-use plots, with an overall correct prediction rate of $91.3 \%$.

Our results indicated that at a road density greater than
$1 \mathrm{~km} / \mathrm{km}^{2}$, no giant panda sign had been found. In line- and curve-fitting analyses, Exp Dec1 model and logistic model had better fits than the linear model (Fig. 2). Both the Exp. Dec and logistic models showed a significant decrease in habitat use intensity at density less than $0.4 \mathrm{~km} / \mathrm{km}^{2}$, whereas at road density more than $0.4 \mathrm{~km} / \mathrm{km}^{2}$, habitat use intensity appeared to be close to zero.

\section{DISCUSSION}

Both disturbance and habitat variables are important predictors of animal distribution (Morrison, 2001; Bhattarai and Kindlmann, 2013; Kolipaka et al., 2017). The habitat requirements of the giant panda have been studied comprehensively (e.g. Ran et al., 2004; Liu et al., 2005; Qi et al., 2009; Gong and Song, 2011; Kang et al., 2011; Zhang et al., 2011; Wei et al., 2017); however, the influence of disturbance density on the giant panda has been little studied.

Our research showed that, compared with non-use plots, less extent of roads, residences, mines, hydropower stations, logging or tree-felling sites were found in the giant panda used plots. However, there was no significant difference between used and non-use plots in some types of disturbances, implying thereby that these disturbances may have little influence on giant panda habitat use. Previous research indicated, from the aspect of disturbance distance, roads had a significant influence on giant panda habitat use (Zhao et al., 2017). Our research demonstrated that road density had a significant influence on the giant panda habitat use among seven kinds of disturbances. Thus, combined with previous findings, we point out that road disturbance was the major factor affecting giant panda habitat use in the Daxiangling Mountains.

According to Forman (1995), there was a threshold between the road density and wildlife populations; above the threshold of $0.6 \mathrm{~km} / \mathrm{km}^{2}$, the populations of 
large animals will decline. Similar results were reported for gray wolves (Wydeven et al., 2001). However, our research demonstrated a different relationship between road density and large animals. Fig. 2 showed that the relationship between road density and the intensity of habitat use by giant pandas could be represented by a curve with either of two shapes. The pattern of the response of habitat use intensity to the road density effectively defines a 'road density tolerance zone'. The upper limit of the tolerance zone is $0.4 \mathrm{~km} / \mathrm{km}^{2}$; the giant panda appeared to almost not use the habitat when the road density was more than $0.4 \mathrm{~km} / \mathrm{km}^{2}$. Moreover, giant panda habitat use intensity declined sharply if roads occurred in the plots. Lin (2006) pointed out that in different situations, the maximum allowable road density may not be the same; if the habitat fragment is less than $1000 \mathrm{~km}^{2}$, the maximum allowable road density should be lower than $0.6 \mathrm{~km} / \mathrm{km}^{2}$. Previous studies indicated that the giant panda habitat in Daxiangling Mountains was isolated from other mountains and spanned less than $1000 \mathrm{~km}^{2}$ (Xu et al., 2006; Zhang et al., 2007; Zhu et al., 2010). Thus, for the giant panda in Daxiangling Mountains, the maximum allowable road density should be lower than $0.4 \mathrm{~km} / \mathrm{km}^{2}$.

According to our study, roads were the main disturbance affecting giant panda habitat use. Therefore, we recommend enhanced regulation to minimize the expansion and impact of roads. Furthermore, the road density should be considered in the protection program.

\section{ACKNOWLEDGEMENTS}

This study was supported by Key Fund Project of Sichuan Provincial Education Department (18ZA0543), Special Fund of Yibin University (2017RC04), and the Sichuan Forestry Department. We thank the fourth giant panda survey team of Sichuan Province.

\section{Statement of conflict of interest}

The authors declares that there is no conflict of interests.

\section{REFERENCE}

Andrews, A., 1990. Fragmentation of habitat by roads and utility corridors: a review. Aust. Zool., 26: 130 141. https://doi.org/10.7882/AZ.1990.005

Bearer, S., Linderman, M., Huang, J.Y., An, L., He, G.M. and Liu, J.G., 2008. Effects of fuelwood collection and timber harvesting on giant panda habitat use. Biol. Conserv., 141: 385-393. https:// doi.org/10.1016/j.biocon.2007.10.009

Beyer, H.L., Ung, R., Murray, D.L. and Fortin, M.J.,
2013. Functional responses, seasonal variation and thresholds in behavioural responses of moose to road density. J. appl. Ecol., 50: 286-294. https:// doi.org/10.1111/1365-2664.12042

Bhattarai, B.P. and Kindlmann, P., 2013. Effect of human disturbance on the prey of tiger in the Chitwan National Park: implications for park management. J. Environ. Manage., 131: 343-350. https://doi. org/10.1016/j.jenvman.2013.10.005

Carr, L.W., Fahrig, L. and Pope, S.E., 2002. Impacts of landscape transformation by roads. In: Applying landscape ecology in biological conservation (ed. K.J. Gutzwiller) pp. 225-243. Springer, New York. https://doi.org/10.1007/978-1-4613-0059-5_13

Forman, R.T.T., 1995. Land mosaics: The ecology of landscapes and regions. Cambrige, UK. https://doi. org/10.1017/9781107050327

Gong, M.H., Hou, M., Lin, C., Song, Y.L. and Ouyang, Z.Y., 2012. The quantitative assessing of trail impacts on giant panda activity based on field track points and GIS. Biodivers. Sci., 20: 420-426. https://doi.org/10.3724/SP.J.1003.2012.07231

Gong, M.H. and Song, Y.L., 2011. Topographic habitat features preferred by the Endangered giant panda Ailuropoda melanoleuca: implications for reserve design and management. Oryx, 45: 252-257. https://doi.org/10.1017/S0030605310001043

Hu, J.C., 2001. Research on the giant panda. Shanghai Publishing House of Science and Technology, Shanghai, China. pp. 182.

Kang, D.W., Kang, W., Tan, L.Y. and Li, J.Q., 2011. The habitat selection of giant panda in Wanglang Nature Reserve, Sichuan province, China. Acta Ecol. Sin., 31: 401-409.

Kolipaka, S.S., Tamis, W.L.M., van't Zelfde, M., Persoon, G.A. and de longh, H.H., 2017. New insights into the factors influencing movements and spatial distribution of reintroduced Bengal tigers (Panthera tigris tigris) in the human-dominated buffer zone of Panna Tiger Reserve, India. Mammalia, 82: 207-217. https://doi.org/10.1515/ mammalia-2016-0126

Li, Y.M., Guo, Z.W., Yang, Q.S., Wang, Y.S. and Niemela, J., 2003. The implications of poaching for giant panda conservation. Biol. Conserv., 111: $125-136 . \quad \mathrm{https} / /$ doi.org/10.1016/S00063207(02)00255-0

Lin, S.C., 2006. The ecologically ideal road density for small islands: the case of Kinmen. Ecol. Eng., 27: 84-92. https://doi.org/10.1016/j. ecoleng.2005.11.002

Liu, X.H., Toxopeus, A.G., Skidmore, A.K., Shao, X.M., 
Dang, G.D., Wang, T. J. and Prins, H.H.T., 2005. Giant panda habitat selection in Foping Nature Reserve, China. J. Wildl. Manage., 69: 1623-1632. https://doi.org/10.2193/0022-541X(2005)69[1623: GPHSIF]2.0.CO;2

Morrison, M.L., 2001. A proposed research emphasis to overcome the limits of wildlife habitat relationship studies. J. Wildl. Manage., 65: 613-623. https://doi. org/10.2307/3803012

Ran, J.H., Liu, S.Y., Wang, H.J., Sun, Z.Y., Zeng, Z.Y. and Liu, S.C., 2003. Effect of grazing on giant pandas' habitat in Yele Nature Reserve. Acta Ecol. Sin., 23: 288-294.

Ran, J.H., Liu, S.Y., Wang, H.J., Zeng, Z.Y., Sun, Z.Y. and Liu, S.C., 2004. A survey of disturbance of giant panda habitat in the Xiaoxiangling Mountains of Sichuan Province. Acta Ecol. Sin., 24: 277-281.

Ran, J.H., Zeng, Z.Y., Liu, S.C. and Wang, H.J., 2006. A survey of the Giant Panda population and habitats in the Daxiangling Mountains. J. Sichuan Univ., 43: 889-893.

Qi, D.W., Hu, Y.B., Gu, X.D., Li, M. and Wei, F.W., 2009. Ecological niche modeling of the sympatric giant and red pandas on a mountain-range scale. Biodivers. Conserv. 18: 2127-2141. https://doi. org/10.1007/s10531-009-9577-7

Qi, D.W., Hu, Y.B., Gu, X.D., Yang, X.Y., Yang, G. and Wei, F.W., 2012. Quantifying landscape linkages among giant panda subpopulations in regional scale conservation. Integr. Zool., 7: 165-174. https://doi. org/10.1111/j.1749-4877.2012.00281.x

Sichuan Provincial Forestry Department., 2015. Sichuan's giant panda-the report of the fourth giant panda survey of Sichuan Province. Sichuan Science and Technology Press, Chengdu.

Suntsov, V.V., Ly, T.V.H. and Adler, G.H., 2009. Distribution of rodents along a gradient of disturbance on the Tay Nguyen Plateau of southern Viet Nam. Mammalia, 67: 379-384. https://doi. org/10.1515/mamm.2003.67.3.379

Swaisgood, R., Wang, D. and Wei, F., 2016. Ailuropoda melanoleuca. In: The IUCN red list of threatened species v. 2017.3. http://www.iucnredlist.org (accessed 15 December 2017).

Van Dyke, F.G., Brocke, R.H., Shaw, H.G., Ackerman, B.B., Hemker, T.P. and Lindzey, F.G., 1986. Reactions of mountain lions to logging and human activity. J. Wildl. Manage., 50:95-102. https://doi. org/10.2307/3801496

Way, J.M., 1977. Roadside verges and conservation in Britain: a review. Biol. Conserv., 12: 65-74. https:// doi.org/10.1016/0006-3207(77)90058-1

Wei, W., Huang, Y.Y., Zhou, H., Yuan, S.B., Zhou, Z.X., Nie, Y.G. and Zhang, Z.J., 2017. Microhabitat separation between giant panda and golden takin in the Qinling Mountains and implications for conservation. North-west. J. Zool., 13: 109-117.

Wydeven, A.P., Mladenoff, D.J., Sickle, T.A., Kohn, B.E., Thiel, R.P. and Hansen, J.L., 2001. Road density as a factor in habitat selection by wolves and other carnivores in the Great Lakes region. Endang. Sp. Upd., 18: 110-114.

Xu, W.H., Ouyang, Z.Y., Jiang, Z.Y., Zheng, H., Liu, J.G., 2006. Assessment of giant panda habitat in the Daxiangling Mountain Range, Sichuan, China. Biodivers. Sci., 14: 223-231. https://doi. org/10.1360/biodiv.050191

Zeng, Z.G., Li, J.S., Yan, W.B., Fan, J.T. and Song, Y.L., 2009. Impact of Lanzhou Chongqing highway and railway on the movement of giant pandas and their habitat protection. Sichuan J. Zool., 28: 641-646.

Zhao, C., Yue, B.S., Ran, J.H., Moermond, T., Hou, N., Yang, X.Y., Gu, X.D., 2017. Relationship between human disturbance and giant panda distribution in the Daxiangling Mountains. Oryx, 51: 146-152. https://doi.org/10.1017/S0030605315000800

Zhao, C., Li, Y.H., Li, D.Y., Guan, J.K., Xiong, Y.Q., Hu, J., 2014. Habitat suitability assessment of Sichuan sika deer in Tiebu Nature Reserve during periods of green and dry grass. Acta Ecol. Sin., 34: 135-140. https://doi.org/10.1016/j.chnaes.2014.03.001

Zhang, W.G., Tang, Z.H., Qi, D.W., Hu, Y.M., Hu, J.C., 2007. Habitat assessment for giant pandas (Ailuropoda melanoleuca) on the northern slope of the Daxiangling Mountains. Acta Ecol. Sin., 27: 146-152.

Zhang, Z.J., Swaisgood, R.R., Zhang, S.N., Nordstrom, L.A., Wang, H.J., Gu, X.D., Hu, J.C., Wei, F.W., 2011. Old-growth forest is what giant pandas really need. Biol. Lett., 7: 403-406. https://doi. org/10.1098/rsbl.2010.1081

Zhu, L.F., Zhan, X.J., Meng, T., Zhang, S.N. and Wei, F.W., 2010. Landscape features influence gene flow as measured by cost-distance and genetic analyses: a case study for giant pandas in the Daxiangling and Xiaoxiangling Mountains. BMC Genet., 11: 72. https://doi.org/10.1186/1471-2156-11-72

Zhu, L.F., Zhang, S.N., Gu, X.D. and Wei, F.W., 2011. Significant genetic boundaries and spatial dynamics of giant pandas occupying fragmented habitat across southwest China. Mol. Ecol., 20: 1122-1132. https://doi.org/10.1111/j.1365-294X.2011.04999.x 